\title{
Spatial Anion Control on Palladium for Mild C-H Arylation of Arenes
}

Dhankhar, Jyoti ; González-Fernández, Elisa ; Dong, Chao-Chen ; Mukhopadhyay, Tufan K ; Linden, Anthony ; Coric, Ilija

\begin{abstract}
C}-\mathrm{H}$ arylation of arenes without the use of directing groups is a challenge, even for simple molecules, such as benzene. We describe spatial anion control as a concept for the design of catalytic sites for $\mathrm{C}-\mathrm{H}$ bond activation, thereby enabling nondirected $\mathrm{C}-\mathrm{H}$ arylation of arenes at ambient temperature. The mild conditions enable late-stage structural diversification of biologically relevant small molecules, and site-selectivity complementary to that obtained with other methods of arene functionalization can be achieved. These results reveal the potential of spatial anion control in transition-metal catalysis for the functionalization of $\mathrm{C}-\mathrm{H}$ bonds under mild conditions.
\end{abstract}

DOI: https://doi.org/10.1021/jacs.0c09611

Posted at the Zurich Open Repository and Archive, University of Zurich

ZORA URL: https://doi.org/10.5167/uzh-198754

Journal Article

Accepted Version

Originally published at:

Dhankhar, Jyoti; González-Fernández, Elisa; Dong, Chao-Chen; Mukhopadhyay, Tufan K; Linden, Anthony; Coric, Ilija (2020). Spatial Anion Control on Palladium for Mild C-H Arylation of Arenes. Journal of the American Chemical Society, 142(45):19040-19046.

DOI: https://doi.org/10.1021/jacs.0c09611 


\title{
Spatial Anion Control on Palladium for Mild C-H Arylation of Arenes
}

\author{
Jyoti Dhankhar, Elisa González-Fernández, Chao-Chen Dong, Tufan K. Mukhopadhyay, Anthony Lin- \\ den, and Ilija Črić*
}

Department of Chemistry, University of Zurich, Winterthurerstrasse 190, CH-8057 Zurich, Switzerland.

\section{Supporting Information Placeholder}

\begin{abstract}
C}-\mathrm{H}$ Arylation of arenes without the use of directing groups is a challenge, even for simple molecules, such as benzene. We describe spatial anion control as a concept for the design of catalytic sites for $\mathrm{C}-\mathrm{H}$ bond activation, thereby enabling nondirected $\mathrm{C}-\mathrm{H}$ arylation of arenes at ambient temperature. The mild conditions enable late-stage structural diversification of biologically relevant small molecules and site-selectivity complementary to that obtained with other methods of arene functionalization can be achieved. These results reveal the potential of spatial anion control in transition-metal catalysis for the functionalization of $\mathrm{C}-\mathrm{H}$ bonds under mild conditions.
\end{abstract}

Catalytic activation of $\mathrm{C}-\mathrm{H}$ bonds with transition metals offers a transformative methodology for organic synthesis, enabling more sustainable and resource-efficient processes. ${ }^{1-5}$ In particular, the direct arylation of $\mathrm{C}-\mathrm{H}$ bonds in arenes represents a streamlined alternative to common $\mathrm{C}\left(\mathrm{sp}^{2}\right)-\mathrm{C}\left(\mathrm{sp}^{2}\right)$ cross-coupling reactions, which require pre-functionalized substrates (Figure 1a). ${ }^{6}$ Palladium shows promise for versatile, non-directed transformations of $\mathrm{C}-\mathrm{H}$ to $\mathrm{C}-\mathrm{C}$ bonds, ${ }^{7-14}$ although the catalytic activity, regioselectivity, application to complex molecules, and reactions such as $\mathrm{C}-\mathrm{H}$ arylation remain challenging. ${ }^{15-19}$ Arylation of arenes without the use of directing groups requires excess arene, high temperatures, acidic, basic, or transition-metal additives, and is limited to certain classes of substrates. ${ }^{18-30} \mathrm{C}-\mathrm{H}$ arylation of simple dialkyl arenes as limiting reactants was recently enabled by a palladium-catalyzed, norbornene derivative-mediated functionalization process, but in the case of benzene, an excess of the substrate was required. ${ }^{18} \mathrm{~A}$ non-directed $\mathrm{C}-\mathrm{H}$ activation followed by a direct arylation process remains a challenge, ${ }^{19}$ even for simple substrates.

Experimental and theoretical studies of palladium-based catalytic $\mathrm{C}-\mathrm{H}$ activation reactions often support a concerted metalation-deprotonation $(\mathrm{CMD})^{31}$ mechanism, where the metal and the coordinated anion cooperatively cleave the $\mathrm{C}-\mathrm{H}$ bond through a six-membered cyclic transition state (Figure 1b). ${ }^{22,32-40}$ Although palladium(II) acetate is a common precatalyst for $\mathrm{C}-\mathrm{H}$ functionalizations and computational studies suggest that simple mononuclear palladium(II) carboxylates could promote facile $\mathrm{C}-\mathrm{H}$ activation, ${ }^{34,36}$ the reactions without additives are inefficient, in part due to the coordination behavior of the carboxylate groups. Carboxylates can block potential substrate coordination sites through $\kappa^{2}$ coordination and behave as bridging ligands to form species of higher nuclearity. ${ }^{41,42}$ Non-directed, palladium-catalyzed $\mathrm{C}-\mathrm{H}$ activation reactions, where the arene is the limiting reactant, are accelerated by using various neutral and anionic ligands. ${ }^{7,8,14,18,26}$ For example, 2-pyridone and combined amino acid-pyridine systems were recently utilized for direct $\mathrm{C}-\mathrm{H}$ olefination and cyanation reactions. ${ }^{7-10,12}$ However, the development of new concepts for non-directed $\mathrm{C}-\mathrm{H}$ activation could further facilitate rational catalyst design, thereby enabling reduced ligand loadings, mild reaction conditions, and challenging late-stage functionalizations, and impact the development of ligand-controlled regioselectivity. With these goals in mind, we describe here a general strategy for the design of palladium(II) sites for $\mathrm{C}-\mathrm{H}$ activation and demonstrate non-directed $\mathrm{C}-\mathrm{H}$ arylation of arenes as limiting reactants at ambient temperature. The method utilizes rationally designed bis(carboxylate) anions, palladium(II) precatalysts, and iodine(III) arylation reagents, and avoids additives such as silver(I) salts. ${ }^{43-48}$

The geometric parameters of the carboxylate coordination on palladium, namely the $\mathrm{O}-\mathrm{Pd}-\mathrm{O}$ angles and $\mathrm{Pd}-\mathrm{O}$ distances, change significantly in the CMD transition state (Figure 1b). We envisioned that the controlled spatial arrangement of constrained bis(anions) could modulate the coordination parameters, as exemplified in Figure 1c, left. The spatial anion control could lead to stabilization of the geometry required for the CMD transition state over, for example, $\kappa^{2}$-coordination in the palladiumbis(carboxylate) catalyst, thus lowering the barrier for $\mathrm{C}-\mathrm{H}$ activation. A comparison to this approach can be drawn with the well-established spatial control of neutral donors in transition metal catalysis where parameters, such as the bite angle, are influenced by the geometric requirements of the ligand backbone (Figure 1c, right). ${ }^{49}$

a) Increase of molecular scaffold complexity by direct $\mathrm{C}-\mathrm{H}$ arylation

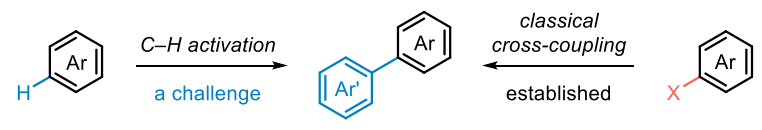

b) Relevance of anion coordination geometry $\quad$ c) Spatial control in metal catalysis for $\mathrm{C}-\mathrm{H}$ activation

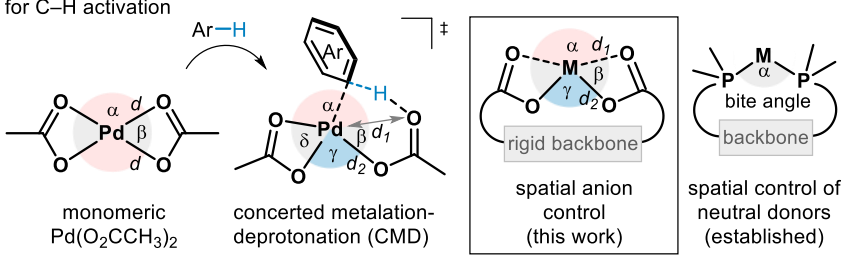

Figure 1. Spatial anion control concept for $\mathrm{C}-\mathrm{H}$ activation. 
Our anion design for spatial anion control on palladium, as shown in Figure 2a, utilizes two 1-naphthyl carboxylic acidderived side-arms, which are structurally constrained by a central aromatic spacer group. The size and geometry of the spacer modulates the relative spatial arrangement of the four carboxylate oxygen atoms, while sterically demanding mesityl groups prevent the carboxylate groups from coordinating in a bridging mode. The crystal structure of the constrained carboxylic acid $\mathbf{H}_{2} \mathbf{L}_{\mathbf{a}}$ (spacer $=$ 2,7-naphthyl) confirms that the carboxylate groups are arranged approximately in a plane, which is parallel to that of the central arene spacer. Palladium precatalysts $\mathbf{1}$ and arylation reagents $\mathbf{2}$, which contain nonafluoro-tert-butoxide anions, were designed with the goal of avoiding the use of silver(I) compounds and any other potentially interfering additives or anions (Figure 2a). The bulky monodentate $\left(\mathrm{CF}_{3}\right)_{3} \mathrm{CO}^{-}$, which does not participate in the six-membered CMD process, can be displaced from palladium by $\mathbf{H}_{2} \mathbf{L}_{\mathbf{a}}$ (see Supporting Information) and act as a mild base $\mathrm{e}^{50}$ to remove $\mathrm{H}^{+}$after the $\mathrm{C}-\mathrm{H}$ activation step, as demonstrated by the Larossa group. ${ }^{51-54}$

The potential of the proposed spatial anion control to address challenging $\mathrm{C}-\mathrm{H}$ functionalization reactions with palladium was examined by performing the non-directed arylation of arenes as limiting reactants. The constrained bis(carboxylic) acid $\mathbf{H}_{2} \mathbf{L}_{\mathbf{a}}$ and palladium precatalyst 1 a enabled catalytic $\mathrm{C}-\mathrm{H}$ arylation of arene 3a with diaryl iodonium reagent $\mathbf{2 a}$ at ambient temperature, yielding $\mathbf{4 a}$ in $39 \%$ yield (Figure $2 b$, Figure S2). In contrast, $\mathbf{H}_{2} \mathbf{L}_{\mathbf{b}}$ and $\mathbf{H}_{2} \mathbf{L}_{\mathbf{c}}$ afforded $\mathbf{4 a}$ in $17 \%$ and $1 \%$ yield, respectively, whereas with $\mathbf{H}_{2} \mathbf{L}_{\mathbf{d}}$ and simpler carboxylates, ${ }^{22,55-57}$ no product was observed (Figure 2c, see Figure S1 for additional screening and control experiments), which attests to the relevance of the relative spatial positioning of the two carboxylate groups for the catalytic reactivity. Furthermore, a derivative of $\mathbf{H}_{2} \mathbf{L}_{\mathbf{a}}$, which lacks the shielding mesityl groups, exhibited no reactivity (Figure S1b). Diaryl iodonium salts with $\mathrm{BF}_{4}{ }^{-}$and $\mathrm{CF}_{3} \mathrm{SO}_{3}{ }^{-}$anions have been used previously for the non-directed functionalization of arenes, but high temperature, an acid co-solvent, and an excess of arene were required. ${ }^{24,27}$ In our system, the common diaryl iodonium salts were unsuitable, while other palladium precatalysts proved to be inferior to 1a, thereby demonstrating the importance of the $\left(\mathrm{CF}_{3}\right)_{3} \mathrm{CO}^{-}$anion.

The constrained anion-enabled catalytic $\mathrm{C}-\mathrm{H}$ arylation is applicable to a wide range of arenes 3 at $26{ }^{\circ} \mathrm{C}$ (Scheme 1). C-H Arylation of substrate $\mathbf{3 a}$ with increased precatalyst loading provided biaryl product $4 \mathrm{a}$ in $55 \%$ isolated yield, while $\mathrm{C}-\mathrm{H}$ functionalization of benzene using $5 \mathrm{~mol} \%$ of $\mathbf{H}_{2} \mathbf{L}_{\mathbf{a}}$ and $10 \mathrm{~mol} \%$ of $\mathbf{1 a}$ afforded mono-arylation and bis-arylation products in a combined yield of $58 \%$ after one day $(\mathbf{4 b})$. Arenes with strongly activating groups undergo efficient arylation at the sterically exposed electron-rich $\mathrm{C}-\mathrm{H}$ site $(\mathbf{4 c}, \mathbf{4 d})$. Aryl and bulky alkyl substituents effectively suppress ortho $\mathrm{C}-\mathrm{H}$ activation (4e-g), although arylation next to smaller alkyl groups, such as methyl, is possible unless an additional meta-substituent is present $(\mathbf{4 h})$. Halogen-substituted arenes are similarly functionalized at the meta and para positions to the halogen group (4i-n). Iodoarenes and aryl triflates can be used as substrates, demonstrating complementary reactivity of the current system to common Pd-catalyzed carbon-carbon bond-forming processes (4l-o). ${ }^{6}$ Fused (hetero)arenes are suitable substrates and yields of up to $86 \%$ could be obtained with naphthalene derivatives $(\mathbf{4} \mathbf{p}-\mathbf{s})$. In cases where two equivalent $\mathrm{C}-\mathrm{H}$ bonds are present, bis-functionalization is observed $(\mathbf{4 p}, \mathbf{4 q}, \mathbf{4 s})$, which further demonstrates the potential for poly-arylation reactions (4p-bis).

The direct $\mathrm{C}-\mathrm{H}$ arylation is compatible with electrophilic functional groups, such as activated ketones and epoxides $(\mathbf{4 t}, \mathbf{4 u})$, and is suitable for late-stage functionalization of functionally rich molecules, as demonstrated with tryptophan derivative $\mathbf{3 v}$ and 1benzazepine-derived compound $\mathbf{3 w}(\mathbf{4 v}, \mathbf{4 w})$. Interestingly, while a) Design of the catalytic system

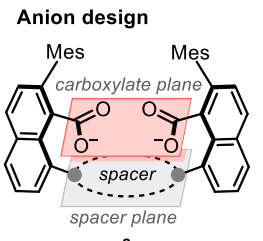

$\mathbf{L}^{2-}$
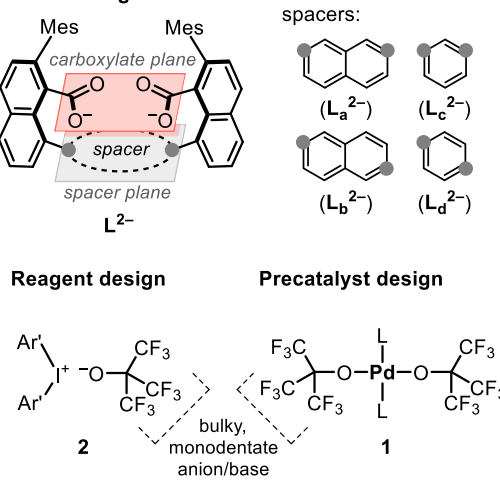
anion/base
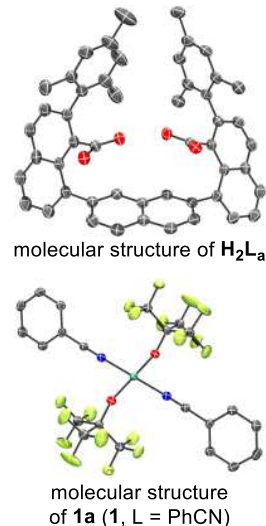

b) $\mathrm{C}-\mathrm{H}$ Arylation at ambient temperature

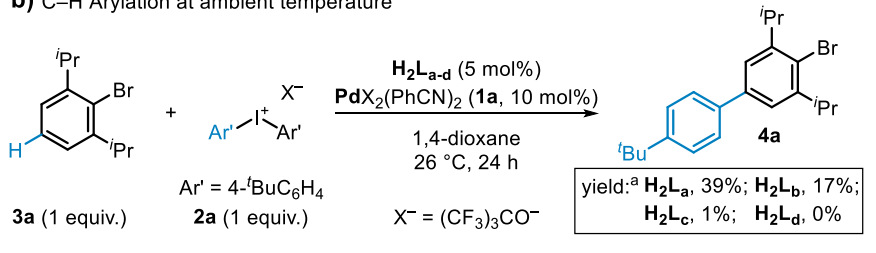

c) Variations from optimal reaction components $\left(\mathrm{H}_{\mathbf{2}} \mathrm{L}_{\mathbf{a}}, \mathbf{1} \mathrm{a}, \mathbf{2 a}\right)^{\mathrm{a}}$

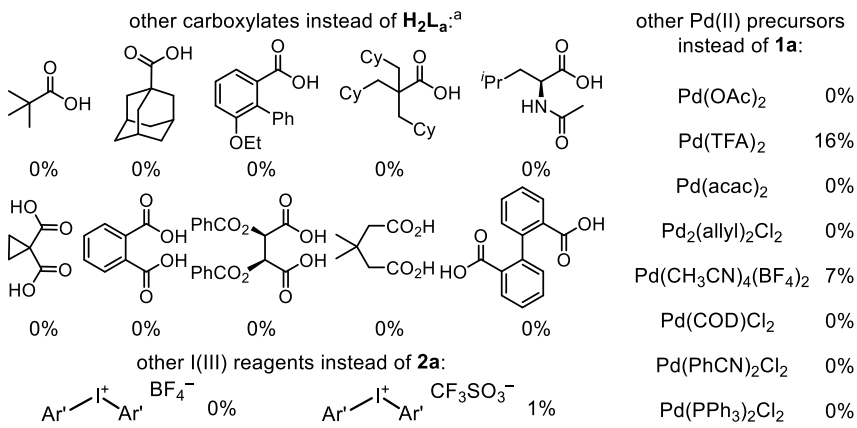

Figure 2. Development of a catalytic system for mild $\mathrm{C}-\mathrm{H}$ aryla-

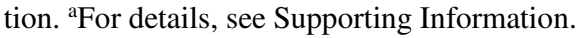

the $\mathrm{C}-\mathrm{H}$ bond para to the electron-donating nitrogen substituent in $\mathbf{3 v}$ was strongly favored, the electronically related arene in $\mathbf{3 w}$ showed comparable reactivity for two other $\mathrm{C}-\mathrm{H}$ bonds. The influence of the substrate structure on the regioselectivity is further exemplified by the arylation of diclofenac and estradiol derivatives. The regioselectivity obtained with diclofenac methyl ester $\mathbf{3 x}$ is directed by the electron-donating free amine group to the para positions of both arenes, while in the cyclic amide derivative $\mathbf{3 y}$, the $\alpha^{\prime}$ and $\beta^{\prime}$ sites are arylated $(\mathbf{4 x}, \mathbf{4 y})$. For the estradiol derivatives, significant arylation is observed ortho to the methylene group in $\mathbf{4 z}$, in comparison to the methyl group in $\mathbf{4 a a}$. In the absence of more sterically accessible sites, the reaction can take place ortho to larger aliphatic groups, as demonstrated by the highly regioselective $\mathrm{C}-\mathrm{H}$ arylation of ibuprofen methyl ester (4ab). The catalytic $\mathrm{C}-\mathrm{H}$ arylation enables the introduction of different aromatic groups, which possess electron-withdrawing or -donating substituents in meta or para positions (4ac-4ai). The subsequent $\mathrm{C}-\mathrm{H}$ arylation of the product at the newly introduced aryl group becomes significant when sterically exposed $\mathrm{C}-\mathrm{H}$ bonds are present (4ad, 4ae). Polybrominated polyaromatic hydrocarbons can be accessed when halogen substituents are present in both reaction substrates (4aj).

Next, the regioselectivity of the $\mathrm{C}-\mathrm{H}$ arylation reaction was compared with other common methods for arene functionalization by using indoprofen ethyl ester as the substrate (Scheme 2, for 
Scheme 1. C-H Arylation reactions at ambient temperature

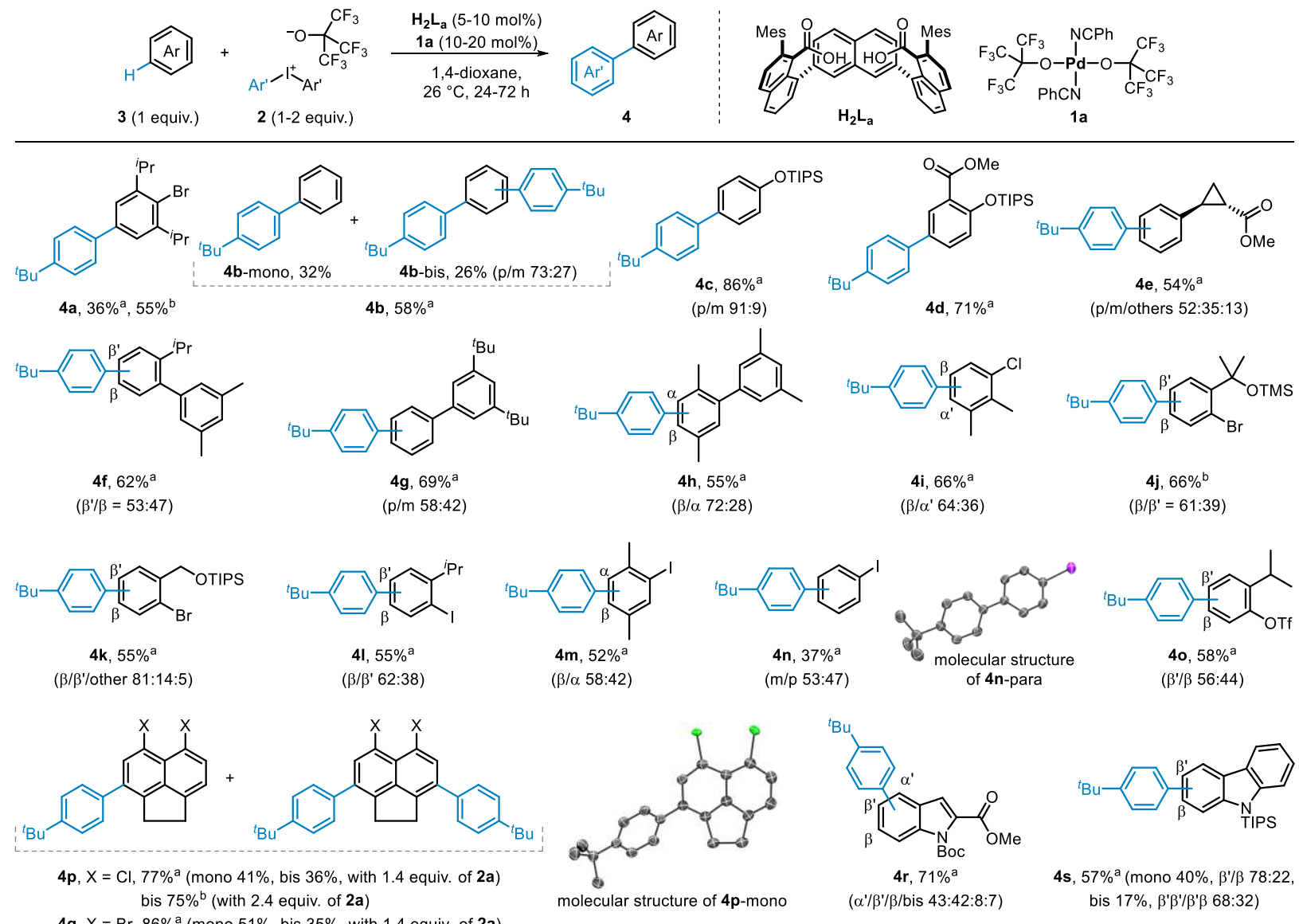

$\mathbf{4 q}, \mathrm{X}=\mathrm{Br}, 86 \%^{\mathrm{a}}$ (mono $51 \%$, bis $35 \%$, with 1.4 equiv. of $\mathbf{2 a}$ )

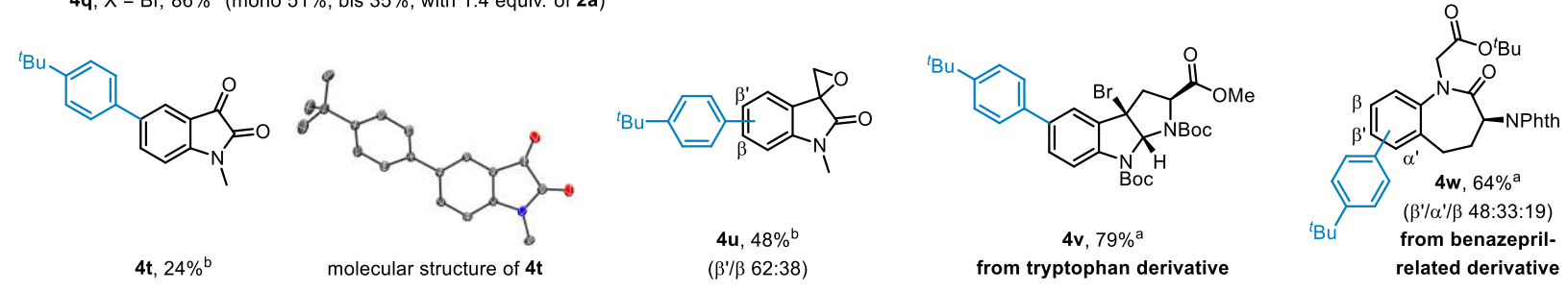<smiles>COC(=O)Cc1cc(-c2ccc(Br)cc2)ccc1Nc1c(Cl)cc(-c2ccc(Br)cc2)cc1Cl</smiles>

$4 x, 57 \%^{a}$ (bis $15 \%$, mono-arylation $42 \%, \beta^{\prime} / \beta^{\prime \prime} 76: 24$ ) from diclofenac methyl ester

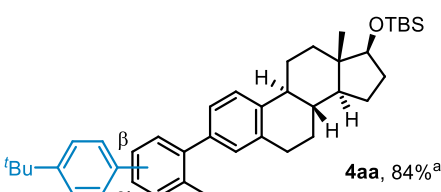

$\left(\beta^{\prime} / \beta /\right.$ others $\left.43: 42: 15\right)$ from estradiol derivative

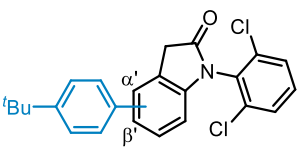

$4 y, 41 \%^{a}\left(\beta^{\prime} / \alpha^{\prime} 55: 45\right)$ from diclofenac derivative

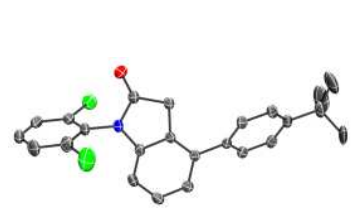

molecular structure of $4 y-\alpha^{\prime}$

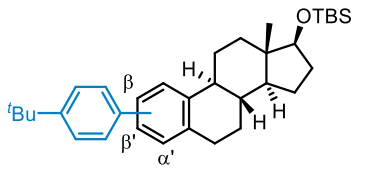

4z, $68 \%^{\mathrm{a}}\left(\beta^{\prime} / \beta / \alpha^{\prime} / \alpha^{\prime} \beta\right.$ 33:32:13:22 from estradiol derivative
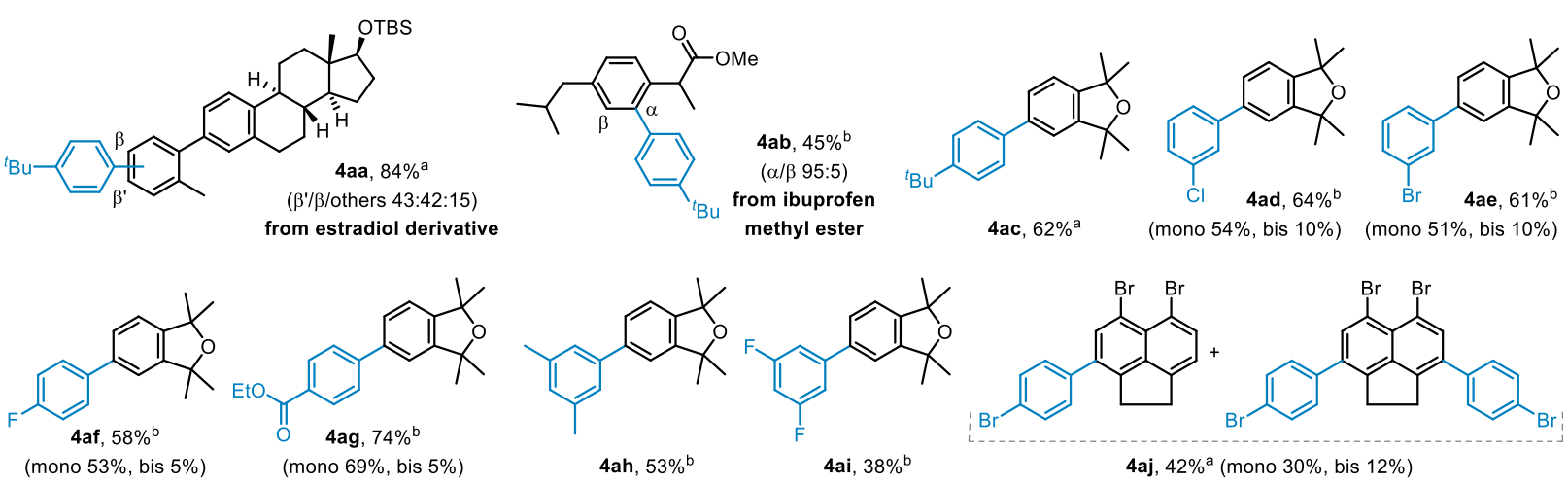

4ah, $53 \%^{\mathrm{b}}$

4ai, $38 \%{ }^{\mathrm{b}}$

4aj, $42 \%^{a}$ (mono $30 \%$, bis $12 \%$ )

${ }^{\mathrm{a}} \mathbf{H}_{2} \mathbf{L}_{\mathbf{a}}(5 \mathrm{~mol} \%), \mathbf{1 a}(10 \mathrm{~mol} \%), 24-72 \mathrm{~h} ;{ }^{\mathrm{b}} \mathbf{H}_{2} \mathbf{L}_{\mathbf{a}}(10 \mathrm{~mol} \%), \mathbf{1 a}(20 \mathrm{~mol} \%), 48-72 \mathrm{~h}$. Combined yields of isolated products are given. 
additional studies about the regioselectivity, see Supporting Information). Direct bromination with $\mathrm{Br}_{2}$ and the reported amidedirected ruthenium-catalyzed $\mathrm{C}-\mathrm{H}$ arylation ${ }^{58}$ result in the functionalization of the more electron-rich arene A. Conversely, iridium-catalyzed $\mathrm{C}-\mathrm{H}$ borylation ${ }^{5}$ functionalizes the $\alpha, \beta$, and $\beta$ positions on the more sterically accessible arene $\mathrm{B}$ (for the regioselectivity under different conditions, see Supporting Information). Despite the presence of more exposed $\mathrm{C}-\mathrm{H}$ bonds, our reaction proceeds at the $\alpha^{\prime}$-position with good regioselectivity, thereby enabling direct $\mathrm{C}-\mathrm{H}$ functionalization of indoprofen ethyl ester with aryl groups, which possess electron-rich (4ak), electron-poor (4al), and fluorinated substituents (4am)

Scheme 2. Site-selectivity in comparison with other methods for arene functionalization

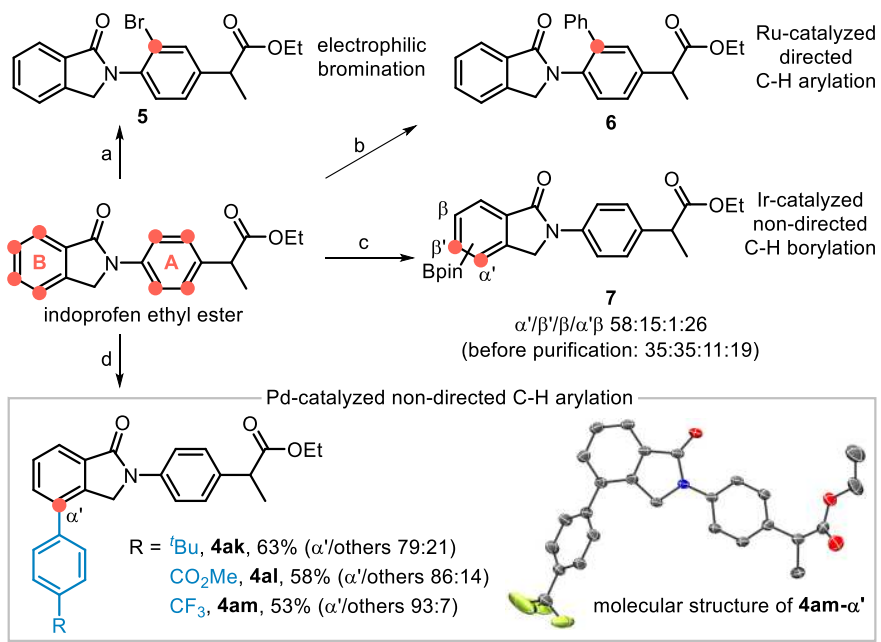

- $=\mathrm{C}\left(\mathrm{sp}^{2}\right)-\mathrm{H}$ sites in the reactant and the main functionalization sites in the products Conditions: a) $\mathrm{Br}_{2}$, DMF, r.t., $20 \mathrm{~h}, 46 \%$; b) $\mathrm{PhB}(\mathrm{OH})_{2}$ (2.5 equiv.), $\left[\mathrm{RuCl}_{2} \text { (p-cymene) }\right]_{2}$ (5 $\left.\mathrm{mol}^{2}\right), \mathrm{AgSbF}_{6}(20 \mathrm{~mol} \%), \mathrm{Ag}_{2} \mathrm{O}$ (1 equiv.), Cu(OTf) $)_{2}(20 \mathrm{~mol} \%), \mathrm{THF}, 90^{\circ} \mathrm{C}, 20 \mathrm{~h}, 85 \%$ (from ref. 58); c) $\mathrm{B}_{2} \mathrm{pin}_{2}$ (0.72 equiv.), [Ir(COD)OMe] ${ }_{2}$ (1 mol\%), dtbbpy $(2 \mathrm{~mol} \%), \mathrm{THF}, 50{ }^{\circ} \mathrm{C}, 2 \mathrm{~h}$ $30 \%$; d) $2 \mathrm{a}, \mathbf{2} \mathbf{i}$, or $\mathbf{2 j}$ (1.2 equiv.), $\mathbf{H}_{2} \mathrm{~L}_{\mathbf{a}}(10 \mathrm{~mol} \%)$, $\mathbf{1 a}(20 \mathrm{~mol} \%), 1,4$-dioxane, $26{ }^{\circ} \mathrm{C}, 72 \mathrm{~h}$.

The proposed mechanism of the $\mathrm{C}-\mathrm{H}$ arylation reaction, which is supported by DFT calculations using benzene and $\mathrm{Ph}_{2} \mathrm{IOC}\left(\mathrm{CF}_{3}\right)_{3}$ as model substrates and $\mathrm{LaPd}_{a}$ as the active catalytic species, is shown in Figure 3a (for details, see Tables S1 and S2). The calculations reveal a potential $\mathrm{Pd}(\mathrm{II}) / \mathrm{Pd}(\mathrm{IV})$ catalytic cycle ${ }^{59}$ with the $\mathrm{C}-\mathrm{H}$ activation as the rate-limiting step $\left(\Delta G^{\ddagger} \mathrm{CMD}=16.6\right.$ $\mathrm{kcal} / \mathrm{mol}$ ). Experimentally, the rate-limiting $\mathrm{C}-\mathrm{H}$ activation on a $\mathbf{L}_{\mathbf{a}}{ }^{2-}$-bound palladium(II) species is supported by the arylation reactivity of the isolated complex $\mathbf{L}_{\mathbf{a}} \mathrm{Pd}\left(\mathrm{CH}_{3} \mathrm{CN}\right)_{2}$ (Figure 4, Figure S1a), faster reaction of $\mathrm{C}_{6} \mathrm{H}_{6}$ compared to $\mathrm{C}_{6} \mathrm{D}_{6}$, a large kinetic isotope effect in a competition experiment $(8 \pm 1)$, and the observed $\mathrm{C}-\mathrm{H}$ functionalization of benzene with methyl acrylate and 1a as reagents in the presence of catalytic $\mathbf{H}_{2} \mathbf{L}_{\mathbf{a}}$ (see Supporting Information). ${ }^{7,8}$ In the calculated pathway, the deprotonation of $\mathrm{HL}_{\mathrm{a}} \mathrm{PdPh}$, formed in the CMD step, by the $\left(\mathrm{CF}_{3}\right)_{3} \mathrm{CO}^{-}$anion of the arylation reagent is followed by the oxidative addition of $\mathrm{Ph}_{2} \mathrm{I}^{+}$to a Pd(II) site through a carboxylate-bridged, six-membered cyclic transition state $\left(\Delta G^{\dagger} \mathrm{OA}-\Delta G_{[\mathrm{LaPdPh}][\mathrm{Ph} 2 \mathrm{I}]}=13.1 \mathrm{kcal} / \mathrm{mol}\right.$, Figure 3a). The spatial anion control and the absence of alternative counter-cations in our system could favor the formation of the ion pair $\left[\mathrm{L}_{\mathrm{a}} \mathrm{PdPh}\right]^{-}\left[\mathrm{Ph}_{2} \mathrm{I}\right]^{+}$, which contains an electron-rich anionic palladium(II) center, ${ }^{60-62}$ thus facilitating the oxidative addition. ${ }^{63}$ At this point, we cannot exclude alternative functionalization mechanisms (see Supporting Information), although dimeric Pd(II) species are less likely with the bulky anion $\mathbf{L}_{\mathbf{a}}{ }^{2-}$ and the current system does not require light. ${ }^{64,65}$ The More O'Ferrall-Jencks plot shows that the $\mathrm{Pd}-\mathrm{C}$ bond formation is more advanced than the $\mathrm{C}-\mathrm{H}$ bond cleavage in the $\mathrm{C}-\mathrm{H}$ activation transition state (Figure $\mathrm{S} 6$ ), which is consistent with the BIES and the $e \mathrm{CMD}$ mechanistic classifications by Ackermann and Carrow, respectively. ${ }^{66,67}$

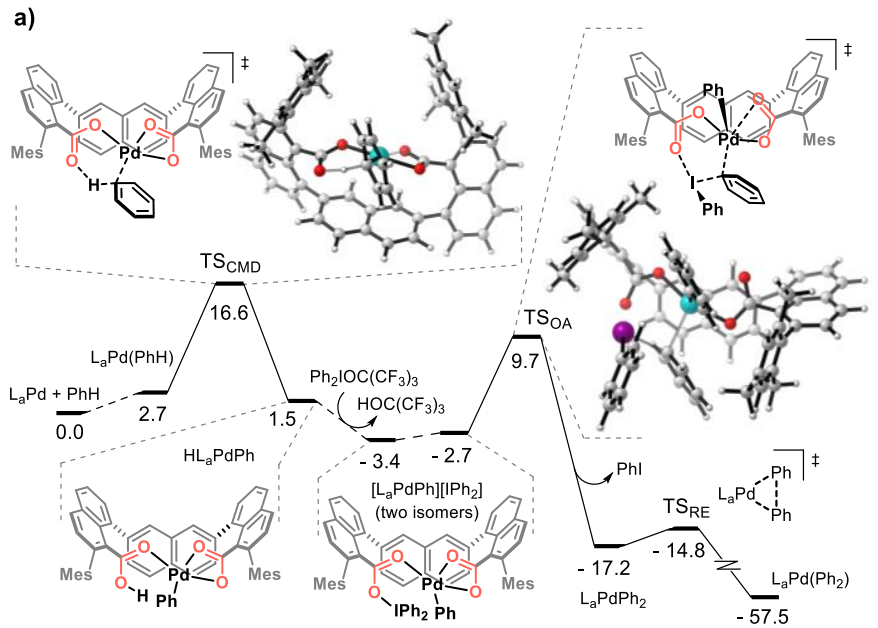

b)

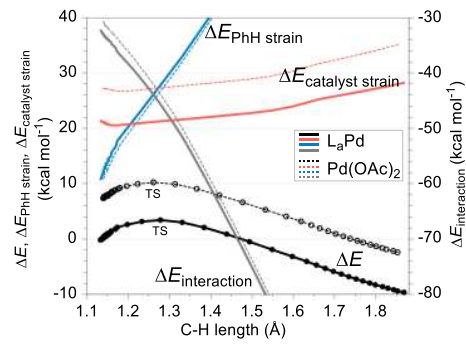

c)

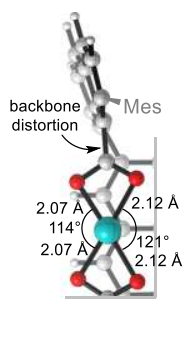

Figure 3. The role of the constrained bis(carboxylate). a) Calculated free energy profile $\left(\mathrm{kcal} \mathrm{mol}^{-1}\right)$ for the proposed mechanism. b) Activation strain analysis of the CMD transition states with $\mathrm{LaPd}$ and mononuclear $\mathrm{Pd}\left(\mathrm{O}_{2} \mathrm{CCH}_{3}\right)_{2}$ with respect to separated $\mathrm{PhH}$ and the catalysts. c) Backbone induced distortion in the computed structure of $\mathrm{LaPd}_{\mathrm{a}}$.

The role of the constrained anion in the key CMD step was investigated by using activation strain analysis, ${ }^{68}$ which revealed that the lower catalyst strain in the transition state, relative to the geometrically relaxed catalyst ( $\left.\Delta E_{\text {catalyst strain }}\right)$, is the main contributing factor to the reduced overall electronic energy $(\Delta E)$ when $\mathrm{L}_{\mathrm{a}} \mathrm{Pd}$ is used, compared with that of mononuclear palladium(II) acetate (Figure 3b). Structural factors resulting from the bent spatial orientation of the two constrained carboxylates, such as distortion of the bis(anion) backbone and deviation from optimal coordination bond lengths and angles, could contribute to the strain in the ground-state of $\mathrm{LaPd}_{\mathrm{P}}$, which is relieved in the CMD transition state (Figure 3c). The spatial anion control imposed by $\mathbf{L a}^{2-}$ is further supported by the uncommon coordination of the two $\kappa^{1}$ carboxylates and two nitriles in $\mathrm{LaPd}_{\mathbf{a}}\left(\mathrm{CH}_{3} \mathrm{CN}\right)_{2}$ (Figure 4, Table $\mathrm{S} 2),{ }^{69}$ with the geometrical parameters, O3-Pd1-O4, 44.55(4) ${ }^{\circ}$,

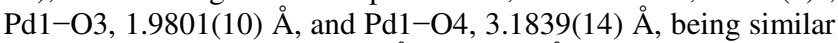
to those in $\mathrm{TS}_{\mathrm{CMD}}, 45.9^{\circ}, 2.06 \AA$, and $3.12 \AA$, respectively (Figure 3a).

Our results demonstrate that structurally constrained carboxylates, combined with precatalysts and reagents that avoid the use of interfering anions or additives, can enable non-directed $\mathrm{C}-\mathrm{H}$ arylation of arenes as limiting reactants at ambient temperature. The mild reaction conditions compare favorably, even against traditional cross-coupling reactions with pre-functionalized arenes, and enable late-stage structural diversification of 


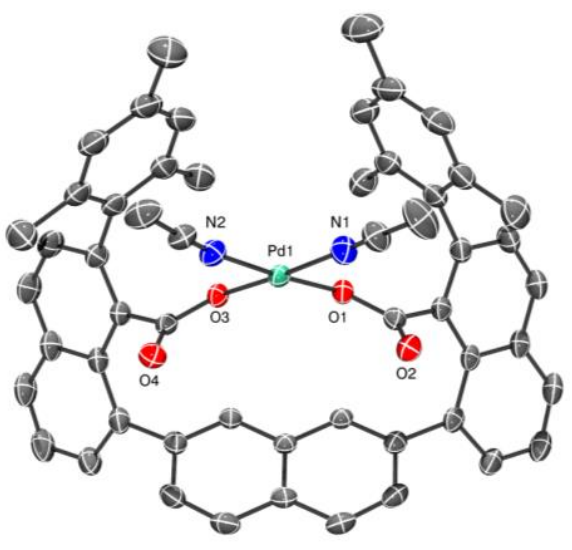

Figure 4. Molecular structure of isolated $\mathrm{L}_{\mathbf{a}} \mathrm{Pd}\left(\mathrm{CH}_{3} \mathrm{CN}\right)_{2}$.

functionally rich molecules. The DFT studies show that spatially controlled carboxylates are powerful cooperative ligands for $\mathrm{C}-\mathrm{H}$ activation on $\mathrm{Pd}(\mathrm{II})$ and could facilitate functionalization through Pd(IV) intermediates. The spatial anion control offers a general concept for the refinement of catalytic cycles and might find broad use in transition-metal catalysis and coordination chemistry.

\section{ASSOCIATED CONTENT}

\section{Supporting Information}

The Supporting Information is available free of charge on the ACS Publications website.

Experimental details, characterization spectra, single crystal data, and computational details (PDF)

Crystallographic data (CIF)

\section{AUTHOR INFORMATION}

\section{Corresponding Author}

Ilija Čorić - Department of Chemistry, University of Zurich, Winterthurerstrasse 190, CH-8057 Zurich, Switzerland; Email: ilija.coric@chem.uzh.ch

\section{Authors}

Jyoti Dhankhar - Department of Chemistry, University of Zurich, Winterthurerstrasse 190, CH-8057 Zurich, Switzerland

Elisa González-Fernández - Department of Chemistry, University of Zurich, Winterthurerstrasse 190, CH-8057 Zurich, Switzerland

Chao-Chen Dong - Department of Chemistry, University of Zurich, Winterthurerstrasse 190, CH-8057 Zurich, Switzerland Tufan K. Mukhopadhyay - Department of Chemistry, University of Zurich, Winterthurerstrasse 190, CH-8057 Zurich, Switzerland

Anthony Linden - Department of Chemistry, University of Zurich, Winterthurerstrasse 190, CH-8057 Zurich, Switzerland

\section{Notes}

The authors are pursuing the protection of intellectual property in relation to this work.

\section{ACKNOWLEDGMENT}

This work was supported by the Department of Chemistry, University of Zurich (UZH), UZH Alumni - FAN (Fonds zur Förderung des akademischen Nachwuchses) (fellowship to I.Č), Dr.
Helmut Legerlotz-Stiftung, Prof. Dr. Hans E. Schmid-Stiftung, Foundation for Research in Science and the Humanities at the UZH, Alfred Werner-Legat, and Holcim Stiftung. E.G.F. acknowledges the support from a Forschungskredit Postdoc UZH, and C.-C.D. is grateful for support by the China Scholarship Council. This work made use of infrastructure services provided by S3IT (www.s3it.uzh.ch), the Service and Support for Science IT team at UZH, as well as an X-ray diffractometer funded by the Swiss National Science Foundation (R'Equip grant no. 206021_164018) and UZH. We thank K. Gademann and C. Nevado for research support, and K. Rehm and U. Stalder for assistance with MS measurements.

\section{REFERENCES}

(1) Cernak, T.; Dykstra, K. D.; Tyagarajan, S.; Vachal, P.; Krska, S. $\mathrm{W}$. The medicinal chemist's toolbox for late stage functionalization of drug-like molecules. Chem. Soc. Rev. 2016, 45, 546.

(2) Abrams, D. J.; Provencher, P. A.; Sorensen, E. J. Recent applications of $\mathrm{C}-\mathrm{H}$ functionalization in complex natural product synthesis. Chem. Soc. Rev. 2018, 47, 8925.

(3) McMurray, L.; O'Hara, F.; Gaunt, M. J. Recent developments in natural product synthesis using metal-catalysed $\mathrm{C}-\mathrm{H}$ bond functionalisation. Chem. Soc. Rev. 2011, 40, 1885.

(4) Stepek, I. A.; Itami, K. Recent Advances in C-H Activation for the Synthesis of $\pi$-Extended Materials. ACS Materials Lett. 2020, $2,951$.

(5) Mkhalid, I. A. I.; Barnard, J. H.; Marder, T. B.; Murphy, J. M.; Hartwig, J. F. C-H Activation for the Construction of $\mathrm{C}-\mathrm{B}$ Bonds. Chem. Rev. 2010, 110, 890.

(6) Campeau, L.-C.; Hazari, N. Cross-Coupling and Related Reactions: Connecting Past Success to the Development of New Reactions for the Future. Organometallics 2019, 38, 3.

(7) Wang, P.; Verma, P.; Xia, G.; Shi, J.; Qiao, J. X.; Tao, S.; Cheng, P. T. W.; Poss, M. A.; Farmer, M. E.; Yeung, K.-S.; Yu, J.-Q. Ligandaccelerated non-directed $\mathrm{C}-\mathrm{H}$ functionalization of arenes. Nature 2017, $551,489$.

(8) Chen, H.; Wedi, P.; Meyer, T.; Tavakoli, G.; van Gemmeren, M. Dual Ligand-Enabled Nondirected $\mathrm{C}-\mathrm{H}$ Olefination of Arenes. Angew. Chem. Int. Ed. 2018, 57, 2497.

(9) Liu, L.-Y.; Yeung, K.-S.; Yu, J.-Q. Ligand-Promoted NonDirected C-H Cyanation of Arenes. Chem. Eur. J. 2018, 25, 2199.

(10) Chen, H.; Mondal, A.; Wedi, P.; van Gemmeren, M. Dual Ligand-Enabled Nondirected C-H Cyanation of Arenes. ACS Catal. 2019, 1979.

(11) Mondal, A.; Chen, H.; Flämig, L.; Wedi, P.; van Gemmeren, M. Sterically Controlled Late-Stage C-H Alkynylation of Arenes. J. Am. Chem. Soc. 2019, 141, 18662.

(12) Zhao, D.; Xu, P.; Ritter, T. Palladium-Catalyzed Late-Stage Direct Arene Cyanation. Chem 2019, 5, 97.

(13) Yuki, T.; Yoshinori, Y.; Kazuyuki, N.; Ken, T.; Yuzo, F. Palladium(II) Catalyzed Carboxylation of Aromatic Compounds with CO under Very Mild Conditions. Chem. Lett. 1995, 24, 345.

(14) Naksomboon, K.; Valderas, C.; Gómez-Martínez, M.; ÁlvarezCasao, Y.; Fernández-Ibáñez, M. Á. S,O-Ligand-Promoted PalladiumCatalyzed C-H Functionalization Reactions of Nondirected Arenes. ACS Catal. 2017, 7, 6342.

(15) Kuhl, N.; Hopkinson, M. N.; Wencel-Delord, J.; Glorius, F. Beyond Directing Groups: Transition-Metal-Catalyzed C-H Activation of Simple Arenes. Angew. Chem. Int. Ed. 2012, 51, 10236.

(16) Wedi, P.; van Gemmeren, M. Arene-Limited Nondirected C-H Activation of Arenes. Angew. Chem. Int. Ed. 2018, 57, 13016.

(17) Kancherla, S.; Jørgensen, K. B.; Fernández-Ibáñez, M. Á. Recent Developments in Palladium-Catalysed Non-Directed C-H Bond Activation in Arenes. Synthesis 2019, 51, 643.

(18) Liu, L.-Y.; Qiao, J. X.; Yeung, K.-S.; Ewing, W. R.; Yu, J.-Q. meta-Selective $\mathrm{C}-\mathrm{H}$ Arylation of Fluoroarenes and Simple Arenes. Angew. Chem. Int. Ed. 2020, 59, 13831.

(19) Kawai, H.; Kobayashi, Y.; Oi, S.; Inoue, Y. Direct C-H bond arylation of arenes with aryltin reagents catalysed by palladium complexes. Chem. Commun. 2008, 1464.

(20) Campeau, L.-C.; Fagnou, K. Palladium-catalyzed direct arylation of simple arenes in synthesis of biaryl molecules. Chem. Commun. 2006, 1253. 
(21) Yang, S.-D.; Sun, C.-L.; Fang, Z.; Li, B.-J.; Li, Y.-Z.; Shi, Z.-J. Palladium-Catalyzed Direct Arylation of (Hetero)Arenes with Aryl Boronic Acids. Angew. Chem. Int. Ed. 2008, 47, 1473.

(22) Lafrance, M.; Fagnou, K. Palladium-Catalyzed Benzene Arylation: Incorporation of Catalytic Pivalic Acid as a Proton Shuttle and a Key Element in Catalyst Design. J. Am. Chem. Soc. 2006, 128, 16496.

(23) Mousseau, J. J.; Vallée, F.; Lorion, M. M.; Charette, A. B Umpolung Direct Arylation Reactions: Facile Process Requiring Only Catalytic Palladium and Substoichiometric Amount of Silver Salts. J. Am. Chem. Soc. 2010, 132, 14412.

(24) Storr, T. E.; Greaney, M. F. Palladium-Catalyzed Arylation of Simple Arenes with Iodonium Salts. Org. Lett. 2013, 15, 1410.

(25) René, O.; Fagnou, K. Room-Temperature Direct Arylation of Polyfluorinated Arenes under Biphasic Conditions. Org. Lett. 2010, 12, 2116.

(26) Liu, L.-Y.; Qiao, J. X.; Yeung, K.-S.; Ewing, W. R.; Yu, J.-Q. meta C-H Arylation of Electron-Rich Arenes: Reversing the Conventional Site Selectivity. J. Am. Chem. Soc. 2019, 141, 14870.

(27) Collins, K. D.; Honeker, R.; Vásquez-Céspedes, S.; Tang, D.-T D.; Glorius, F. C-H arylation of triphenylene, naphthalene and related arenes using $\mathrm{Pd} / \mathrm{C}$. Chem. Sci. 2015, 6, 1816.

(28) Kenji, F.; Hiroshi, K.; Tetsuo, S.; Shuichi, O. Palladiumcatalyzed Direct $\mathrm{C}-\mathrm{H}$ Bond Arylation of Simple Arenes with Aryltrimethylsilanes. Chem. Lett. 2011, 40, 1050.

(29) Li, R.; Jiang, L.; Lu, W. Intermolecular Cross-Coupling of Simple Arenes via $\mathrm{C}-\mathrm{H}$ Activation by Tuning Concentrations of Arenes and TFA. Organometallics 2006, 25, 5973.

(30) Ball, L. T.; Lloyd-Jones, G. C.; Russell, C. A. Gold-Catalyzed Direct Arylation. Science 2012, 337, 1644.

(31) The term CMD is used here in the broad sense, for example, see references 32 and 38. For detailed mechanistic classifications, see references 66 and 67 .

(32) Lapointe, D.; Fagnou, K. Overview of the Mechanistic Work on the Concerted Metallation-Deprotonation Pathway. Chem. Lett. 2010, 39 1118.

(33) Ackermann, L. Carboxylate-Assisted Transition-MetalCatalyzed $\mathrm{C}-\mathrm{H}$ Bond Functionalizations: Mechanism and Scope. Chem. Rev. 2011, 111, 1315

(34) Davies, D. L.; Macgregor, S. A.; McMullin, C. L. Computational Studies of Carboxylate-Assisted $\mathrm{C}-\mathrm{H}$ Activation and Functionalization at Group 8-10 Transition Metal Centers. Chem. Rev. 2017, 117, 8649.

(35) García-Cuadrado, D.; Braga, A. A. C.; Maseras, F.; Echavarren, A. M. Proton Abstraction Mechanism for the Palladium-Catalyzed Intramolecular Arylation. J. Am. Chem. Soc. 2006, 128, 1066.

(36) Biswas, B.; Sugimoto, M.; Sakaki, S. C-H Bond Activation of Benzene and Methane by $\mathrm{M}\left(\eta^{2}-\mathrm{O}_{2} \mathrm{CH}\right)_{2}(\mathrm{M}=\mathrm{Pd}$ or $\mathrm{Pt})$. A Theoretical Study. Organometallics 2000, 19, 3895.

(37) Davies, D. L.; Donald, S. M. A.; Macgregor, S. A. Computational Study of the Mechanism of Cyclometalation by Palladium Acetate. J. Am. Chem. Soc. 2005, 127, 13754

(38) Gorelsky, S. I.; Lapointe, D.; Fagnou, K. Analysis of the Concerted Metalation-Deprotonation Mechanism in Palladium-Catalyzed Direct Arylation Across a Broad Range of Aromatic Substrates. J. Am. Chem. Soc. 2008, 130, 10848

(39) Gómez, M.; Granell, J.; Martinez, M. Variable-Temperature and -Pressure Kinetics and Mechanism of the Cyclopalladation Reaction of Imines in Aprotic Solvent. Organometallics 1997, 16, 2539.

(40) Boutadla, Y.; Davies, D. L.; Macgregor, S. A.; PobladorBahamonde, A. I. Mechanisms of $\mathrm{C}-\mathrm{H}$ bond activation: rich synergy between computation and experiment. Dalton Trans. 2009, 5820.

(41) Baxter, R. D.; Sale, D.; Engle, K. M.; Yu, J.-Q.; Blackmond, D. G. Mechanistic Rationalization of Unusual Kinetics in Pd-Catalyzed C-H Olefination. J. Am. Chem. Soc. 2012, 134, 4600.

(42) Carole, W. A.; Colacot, T. J. Understanding Palladium Acetate from a User Perspective. Chem. Eur. J. 2016, 22, 7686

(43) Bay, K. L.; Yang, Y.-F.; Houk, K. N. Multiple roles of silver salts in palladium-catalyzed $\mathrm{C}-\mathrm{H}$ activations. J. Organomet. Chem. 2018 $864,19$.

(44) Bhaskararao, B.; Singh, S.; Anand, M.; Verma, P.; Prakash, P.; C, A.; Malakar, S.; Schaefer, H. F.; Sunoj, R. B. Is silver a mere terminal oxidant in palladium catalyzed $\mathrm{C}-\mathrm{H}$ bond activation reactions? Chem. Sci. 2020, 11, 208 .

(45) Whitaker, D.; Burés, J.; Larrosa, I. Ag(I)-Catalyzed C-H Activation: The Role of the $\mathrm{Ag}(\mathrm{I})$ Salt in $\mathrm{Pd} / \mathrm{Ag}-\mathrm{Mediated} \mathrm{C}-\mathrm{H}$ Arylation of Electron-Deficient Arenes. J. Am. Chem. Soc. 2016, 138, 8384.
(46) Lotz, M. D.; Camasso, N. M.; Canty, A. J.; Sanford, M. S. Role of Silver Salts in Palladium-Catalyzed Arene and Heteroarene C-H Functionalization Reactions. Organometallics 2017, 36, 165.

(47) Lee, S. Y.; Hartwig, J. F. Palladium-Catalyzed, Site-Selective Direct Allylation of Aryl C-H Bonds by Silver-Mediated C-H Activation: A Synthetic and Mechanistic Investigation. J. Am. Chem. Soc. 2016, 138, 15278.

(48) Yang, Y.-F.; Cheng, G.-J.; Liu, P.; Leow, D.; Sun, T.-Y.; Chen, P.; Zhang, X.; Yu, J.-Q.; Wu, Y.-D.; Houk, K. N. Palladium-Catalyzed Meta-Selective $\mathrm{C}-\mathrm{H}$ Bond Activation with a Nitrile-Containing Template: Computational Study on Mechanism and Origins of Selectivity. J. Am. Chem. Soc. 2014, 136, 344

(49) van Leeuwen, P. W. N. M.; Kamer, P. C. J.; Reek, J. N. H.; Dierkes, P. Ligand Bite Angle Effects in Metal-catalyzed C-C Bond Formation. Chem. Rev. 2000, 100, 2741.

(50) Filler, R.; Schure, R. M. Highly acidic perhalogenated alcohols. A new synthesis of perfluoro-t-butyl alcohol. J. Org. Chem. 1967, 32 1217.

(51) Panigrahi, A.; Whitaker, D.; Vitorica-Yrezabal, I. J.; Larrosa, I. $\mathrm{Ag} / \mathrm{Pd}$ Cocatalyzed Direct Arylation of Fluoroarene Derivatives with Aryl Bromides. ACS Catal. 2020, 10, 2100.

(52) Simonetti, M.; Perry, G. J. P.; Cambeiro, X. C.; Juliá-Hernández, F.; Arokianathar, J. N.; Larrosa, I. Ru-Catalyzed C-H Arylation of Fluoroarenes with Aryl Halides. J. Am. Chem. Soc. 2016, 138, 3596.

(53) Simonetti, M.; Cannas, D. M.; Panigrahi, A.; Kujawa, S.; Kryjewski, M.; Xie, P.; Larrosa, I. Ruthenium-Catalyzed C-H Arylation of Benzoic Acids and Indole Carboxylic Acids with Aryl Halides. Chem. Eur. J. 2017, 23, 549 .

(54) Ghosh, K. K.; Uttry, A.; Koldemir, A.; Ong, M.; van Gemmeren, M. Direct $\beta-\mathrm{C}\left(\mathrm{sp}^{3}\right)-\mathrm{H}$ Acetoxylation of Aliphatic Carboxylic Acids. Org. Lett. 2019, 21, 7154.

(55) Pi, J.-J.; Lu, X.-Y.; Liu, J.-H.; Lu, X.; Xiao, B.; Fu, Y.; Guimond, N. Exploration of Biaryl Carboxylic Acids as Proton Shuttles for the Selective Functionalization of Indole C-H Bonds. J. Org. Chem 2018, 83, 5791 .

(56) Yutaka, T.; Naoya, M.; Tetsuaki, F.; Yasushi, T. Steric Effect of Carboxylate Ligands on Pd-Catalyzed Intramolecular $\mathrm{C}\left(\mathrm{sp}^{2}\right)-\mathrm{H}$ and $\mathrm{C}\left(\mathrm{sp}^{3}\right)-\mathrm{H}$ Arylation Reactions. Angew. Chem. Int. Ed. 2018, 57, 10314

(57) Bing-Feng, S.; Nathan, M.; Yang-Hui, Z.; Jin-Quan, Y. PdIICatalyzed Enantioselective Activation of $\mathrm{C}\left(\mathrm{sp}^{2}\right)-\mathrm{H}$ and $\mathrm{C}\left(\mathrm{sp}^{3}\right)-\mathrm{H}$ Bonds Using Monoprotected Amino Acids as Chiral Ligands. Angew. Chem. Int. Ed. 2008, 47, 4882 .

(58) Yuan, Y.-C.; Bruneau, C.; Roisnel, T.; Gramage-Doria, R. SiteSelective Ruthenium-Catalyzed $\mathrm{C}-\mathrm{H}$ Bond Arylations with Boronic Acids: Exploiting Isoindolinones as a Weak Directing Group. J. Org. Chem. 2019, 84, 12893.

(59) Deprez, N. R.; Kalyani, D.; Krause, A.; Sanford, M. S. Room Temperature Palladium-Catalyzed 2-Arylation of Indoles. J. Am. Chem. Soc. 2006, 128,4972

(60) Bayler, A.; Canty, A. J.; Ryan, J. H.; Skelton, B. W.; White, A. H. Arylation of palladium(II) and platinum(II) by diphenyliodonium triflate to form metal(IV) species, and a structural analysis of an isomer of $\mathrm{PtIMe}_{2} \mathrm{Ph}$ (bpy) (bpy=2,2'-bipyridine). Inorg. Chem. Commun. 2000, 3 575

(61) Canty, A. J. Organopalladium and platinum chemistry in oxidising milieu as models for organic synthesis involving the higher oxidation states of palladium. Dalton Trans. 2009, 10409.

(62) Canty, A. J.; Patel, J.; Rodemann, T.; Ryan, J. H.; Skelton, B. W.; White, A. H. Reactivity of Diaryliodine(III) Triflates toward Palladium(II) and Platinum(II): Reactions of $\mathrm{C}\left(\mathrm{sp}^{2}\right)-\mathrm{I}$ Bonds to Form Arylmetal(IV) Complexes; Access to Dialkyl(aryl)metal(IV), 1,4Benzenediyl-Bridged Platinum(IV), and Triphenylplatinum(IV) Species; and Structural Studies of Platinum(IV) Complexes. Organometallics 2004 $23,3466$.

(63) Szabó, K. J. Mechanism of the oxidative addition of hypervalent iodonium salts to palladium(II) pincer-complexes. J. Mol. Catal. A Chem. 2010, 324,56

(64) Deprez, N. R.; Sanford, M. S. Synthetic and Mechanistic Studies of Pd-Catalyzed $\mathrm{C}-\mathrm{H}$ Arylation with Diaryliodonium Salts: Evidence for a Bimetallic High Oxidation State Pd Intermediate. J. Am. Chem. Soc 2009, 131, 11234

(65) Neufeldt, S. R.; Sanford, M. S. Combining Transition Metal Catalysis with Radical Chemistry: Dramatic Acceleration of PalladiumCatalyzed C-H Arylation with Diaryliodonium Salts. Adv. Synth. Catal. 2012, 354, 3517. 
(66) Rogge, T.; Oliveira, J. C. A.; Kuniyil, R.; Hu, L.; Ackermann, L. Reactivity-Controlling Factors in Carboxylate-Assisted $\mathrm{C}-\mathrm{H}$ Activation under $4 \mathrm{~d}$ and $3 \mathrm{~d}$ Transition Metal Catalysis. ACS Catal. 2020, 10, 10551.

(67) Carrow, B. P.; Sampson, J.; Wang, L. Base-Assisted C-H Bond Cleavage in Cross-Coupling: Recent Insights into Mechanism, Speciation, and Cooperativity. Isr. J. Chem. 2020, 60, 230.

(68) Bickelhaupt, F. M.; Houk, K. N. Analyzing Reaction Rates with the Distortion/Interaction-Activation Strain Model. Angew. Chem. Int. Ed. 2017, 56, 10070.

(69) Morohashi, N.; Iijima, S.; Akasaka, K.; Hattori, T. Selective extraction of $\mathrm{Pd}(\mathrm{II})$ by $p$-tert-butylcalix[4]arenedicarboxylic acid. New $J$. Chem. 2017, 41, 2231. 
For Table of Contents Only:

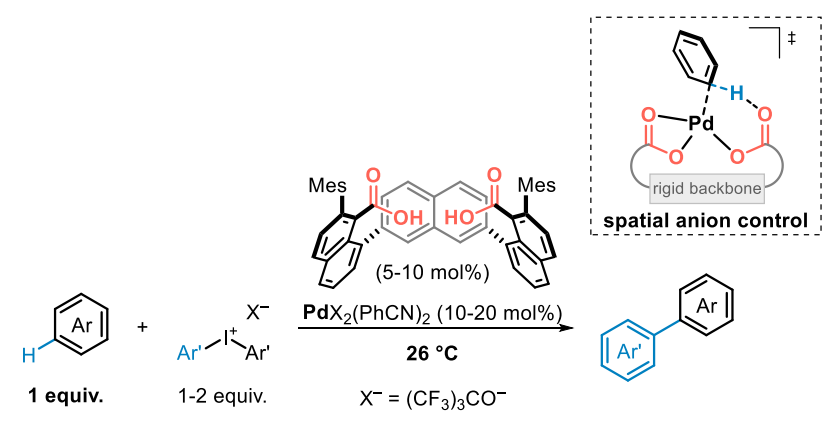

